\title{
Prevalence of gestational, placental and congenital malaria in north-west Colombia
}

\author{
Olga Agudelo, Eliana Arango, Amanda Maestre* and Jaime Carmona-Fonseca
}

\begin{abstract}
Background: The frequency of pregnancy-associated malaria is increasingly being documented in American countries. In Colombia, with higher frequency of Plasmodium vivax over Plasmodium falciparum infection, recent reports confirmed gestational malaria as a serious public health problem. Thick smear examination is the gold standard to diagnose malaria in endemic settings, but in recent years, molecular diagnostic methods have contributed to elucidate the dimension of the problem of gestational malaria. The study was aimed at exploring the prevalence of gestational, placental and congenital malaria in women who delivered at the local hospitals of north-west Colombia, between June 2008 and April 2011.
\end{abstract}

Methods: A group of 129 parturient women was selected to explore the prevalence of gestational, placental and congenital malaria in a descriptive, prospective and transversal (prevalence) design. Diagnosis was based on the simultaneous application of two independent diagnostic tests: microscopy of thick blood smears and a polymerase chain reaction assay ( $\mathrm{PCR}$ ).

Results: The prevalence of gestational malaria (thick smear /PCR) was 9.1\%/14.0\%; placental malaria was 3.3\%/16.5\% and congenital malaria was absent. A history of gestational malaria during the current pregnancy was significantly associated with gestational malaria at delivery. Plasmodium vivax caused $65 \%$ of cases of gestational malaria, whereas $P$. falciparum caused most cases of placental malaria.

Conclusions: Gestational and placental malaria are a serious problem in the region, but the risk of congenital malaria is low. A history of malaria during pregnancy may be a practical indicator of infection at delivery.

Keywords: Pregnancy, Malaria, Plasmodium, Prevalence, Colombia

\section{Background}

Women inhabiting malaria endemic areas are at variable risk of acquiring gestational malaria according to the degree of endemicity and their parity. In regions of high stable transmission, they might acquire significant clinical immunity before pregnancy, and placental malaria is often asymptomatic, but it can produce severe maternal anaemia and foetal growth restriction [1]. In such regions, placental malaria is common in first-time mothers, and women develop specific immunity against placental infection over successive pregnancies. On the other hand, in areas of low unstable transmission, malaria is often symptomatic, regardless of parity, and it might result in foetal loss and maternal death [2].

\footnotetext{
* Correspondence: aemaestre@gmail.com

* Correspondence: aemaestre@gmail.com
Grupo Salud y Comunidad, Facultad de Medicina, Universidad de Antioquia, Medellín, Colombia
}

In the Americas, the problem of gestational malaria has been the subject of few reports [3-6]. The frequency of gestational malaria and placental malaria in the region of Uraba, north-west Colombia, is relatively high, affecting 10-12 out of 100 pregnant women, when measured by microscopy [7]. A report based on samples from the same region (2004-2006) found a prevalence of gestational malaria of $14.0 \%$ and placental malaria of $10.5 \%$ (by thick smear microscopy) [8]. Another study on Plasmodium infection at the time of delivery, reported a prevalence of gestational malaria of $13 \%$ with microscopy, but the frequency increased to $32 \%$ with a polymerase chain reaction (PCR) assay [9]. In addition, the histopathological examination of placental tissue showed unmistakable signs of placental malaria in $19 \%$ of the 79 specimens studied, in which $33 \%$ were characterized as acute, $7 \%$ as chronic and $60 \%$ as past infections [9]. The

\section{Biomed Central}


diagnostic capacity of histopathology was superior to that of microscopy and PCR, mainly because the basis of the histopathology diagnosis is the observation of the parasite and/or the malarial pigment.

Recent evidence gathered in the country, confirmed the deleterious effect of the infection, in both $P$. vivax and $P$. falciparum malaria, in pregnant subjects, with presence of organ specific complications [10], congenital malaria [11], and low birth weight and prematurity [12]. All the above data confirmed gestational and placental malaria as a serious public health problem in north-west Colombia, where most of the country's cases of malaria are reported. In addition, these reports confirmed that both $P$. falciparum and $P$. vivax are the causative species in these conditions, with $65-70 \%$ of reported cases due to $P$. vivax $[13,14]$.

Resistance of $P$. falciparum to anti-malarials is widespread in the country $[15,16]$, and artemisinin-based combination therapy is recommended from 2006, with two different schemes applied between 2006-2009: a three-day course of artesunate plus mefloquine for the Antioquia department and a three-day course of artemether plus lumefantrine for the Cordoba department. As for gestational malaria, women in their $2^{\text {nd }}$ and $3^{\text {rd }}$ trimester of pregnancy were treated as nonpregnant subjects according to the place of residency, or with a 7-day course of quinine plus clindamycin if on their $1^{\text {st }}$ trimester of pregancy. In 2009, the scheme artesunate plus mefloquine was withdrawn as first-line from the national treatment guidelines and artemether plus lumefantrine is used throughout the country. Vivax malaria remains sensitive to a three-day course of chloroquine [17] and, in non-pregnant subjects, is administered in combination with a 14-day course of primaquine [18].

A study carried out in three municipalities of the Uraba region (north-west Colombia) recruited and followed $>2,000$ pregnant women at the antenatal clinics and hospitals to obtain a measure of incidenced from a group of 250 pregnant women recruited at delivery. Two studies explored the prevalence of gestational malaria and placental malaria at delivery in the Uraba region $[8,9]$, yet no data are available from the Cordoba region, which, together with Uraba and Bajo Cauca, constitute the majority of malaria cases in Colombia $[13,14]$.

The current study reports on the results of a study aimed at exploring the prevalence of gestational, placental and congenital malaria in women who delivered at the local hospitals of north-west Colombia, between June 2008 and April 2011. Diagnosis was based on the simultaneous application of two independent diagnostic tests: microscopy of thick blood smear and a PCR.

\section{Methods}

\section{Study area}

The study was carried out in north-west Colombia in the localities of Turbo (Antioquia department) and Puerto Libertador (Cordoba department) (Figure 1). Between Antioquia and Cordoba lays the malaria endemic region known as Uraba-Altos Sinu/San Jorge-Bajo Cauca, which has an estimated area of 43,506 km2 and a malaria at-risk population of 2.5 million distributed in 35 municipalities. The Antioquia department reported 20,511 (in 2008), 32,029 (in 2009) and 45,618 (in 2010) cases of malaria [19]. Plasmodium vivax was reported in $65-70 \%$ of total cases. Meanwhile, in Cordoba, during 2001-2009, in $1,433,461$ inhabitants, a mean number of 37,616 cases/ year were reported: $69 \%$ caused by $P$. vivax, $23 \%$ by $P$. falciparum and $1 \%$ from mixed infection. The municipalities of Valencia and Tierralta (south-west Cordoba, on the border with Uraba), and Puerto Libertador (south-east Cordoba) reported $90 \%$ of malaria cases in the region [20].

Subjects for the current study were recruited at the local hospitals "ESE Hospital Francisco Valderrama", in Turbo, and "CAMU Divino Niño", in Puerto Libertador. In these localities, the annual mean parasitic indexes (malaria cases/1000 inhabitants) during 2000-2009 were 46.6 in Turbo and 23.4 in Puerto Libertador [19,20].

\section{Study design and sample selection}

The study was part of a larger project aimed at exploring the epidemiology (incidence and prevalence measures), clinical aspects (mother and child outcomes), and immunopathology (placental damage and immune regulation secondary to infection) of gestational and placental malaria in north-west Colombia, partial results have been reported on the frequency of infection and the histopathology of placental malaria [7,9,21]. A total 2,000 pregnant women were recruited for the main study at the localities of Turbo and Puerto Libertador. Subjects were recruited in a sequential fashion until the sample size for the main study was reached. Clinical and epidemiological surveys were applied to all those women. Data from medical records were also obtained in order to assess the clinical outcome of the pregnancy.

A subset of subjects was selected to explore the prevalence of the conditions in a descriptive, prospective and transversal (prevalence) design. A sample size of 129 pregnant women was calculated based on the following parameters: a total of 2,000 in-hospital deliveries during the 34 months of the study; $10 \%$ expected frequency of malaria (gestational malaria or placental malaria); $95 \%$ confidence interval; $5 \%$ sampling error. Subjects were selected and included in this study using a simple random sampling method from the records of the 2,000 women recruited in the main project. The prevalence of infection by Plasmodium was assessed intra-partum using 


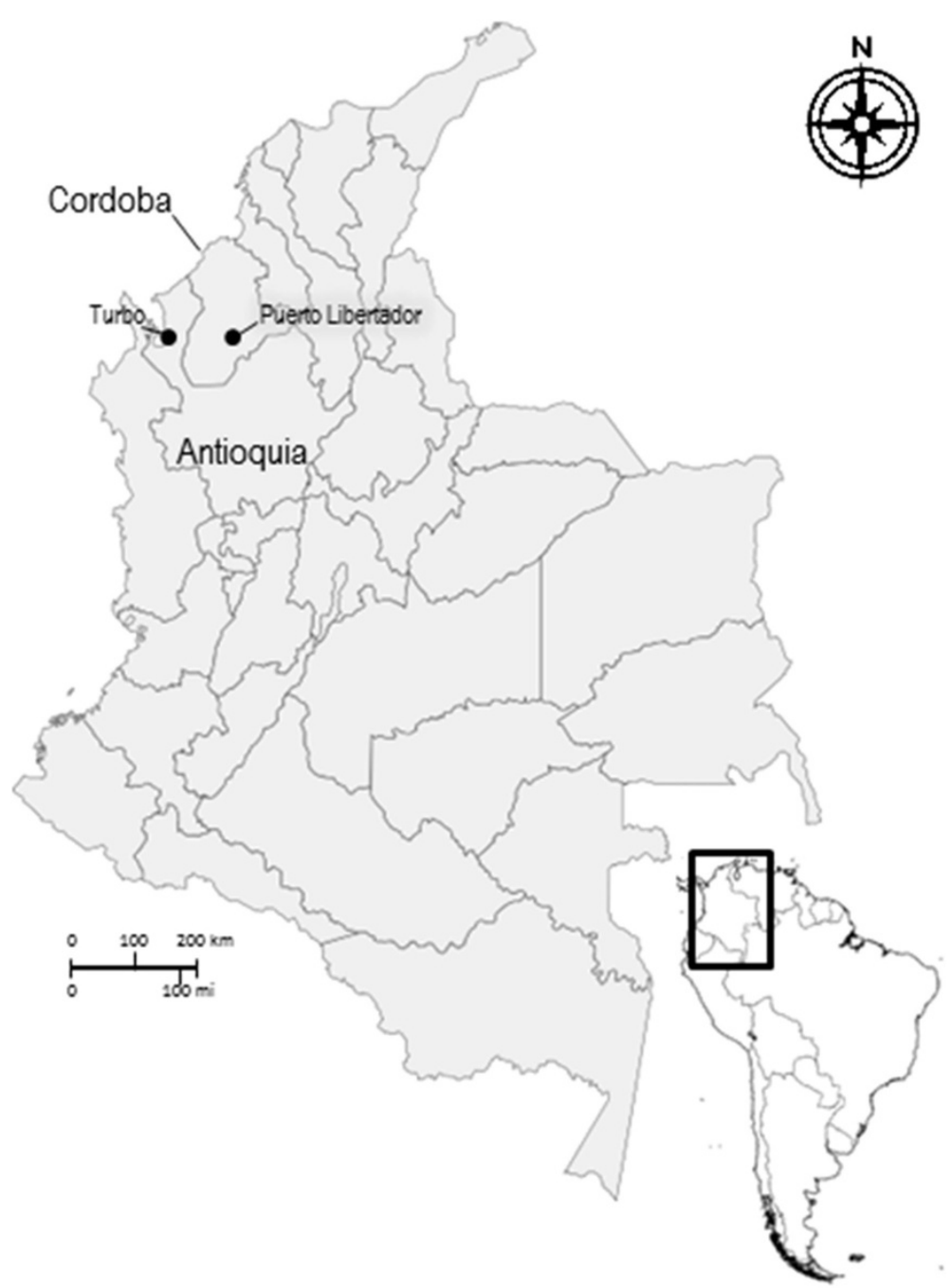

Figure 1 Map of Colombia. Turbo (Uraba region) of Antioquia department and Puerto Libertador (Cordoba) where the study took place, are located in north-west Colombia.

two independent tests: microscopy of thick smears and PCR. For this, paired blood samples were obtained from peripheral vein of the mother and from the placenta at time of delivery.

\section{Inclusion and exclusion criteria}

Inclusion criteria were $>1$ year residency in the study region, general good health and no history of serious disease, signature of the voluntary consent form and hospital delivery. The only exclusion criterion was withdrawal of the voluntary consent.

\section{Term definitions}

The following definitions were applied: A) Low birth weight: $<2,500$ grams. B) Premature neonate: $<37$ weeks. C) Intra-uterine growth restriction: $\geq 37$ weeks of gestation and low birth weight. D) Abortion: delivery before 22 weeks of pregnancy. E) Stillbirth: dead neonate of $>22$ weeks. F) Anaemia: haemoglobin $<11 \mathrm{~g} / \mathrm{dL}$. G) Full term pregnancy: $>38$ weeks. H) Gestational or pregnancy malaria: plasmodial infection diagnosed in a pregnant woman after examination of maternal peripheral blood. I) Placental malaria: plasmodial infection diagnosed in placenta after examination of placental blood.

\section{Sample preparation}

Whole blood samples from mother's peripheral blood and placenta were obtained at delivery rooms in the local hospitals of Puerto Libertador and Turbo. The mother's sample was obtained by finger prick and placental blood was obtained from the lake formed following a wash with saline $(0.9 \%)$ and removal of a $3 \times 3 \times 3$ $\mathrm{cm}$ section in the area of the cord's insertion on the maternal side of the organ. These samples were used to 
perform thick and thin smear examination and PCR as detailed below.

\section{Diagnosis of Plasmodium infection}

The presence of Plasmodium was confirmed in maternal, placental and cord blood by thick smear and a nested PCR according to standard published methods $[9,22,23]$. Diagnosis by microscopy was carried out in the field site by a trained technician with certified experience in malaria diagnosis. Parasitaemia was calculated after observation of fields corresponding to 200 leukocytes and a constant of 8,000 leucocytes $/ \mu \mathrm{L}$. A sample was considered negative after observation of 500 high power fields.

Diagnosis of infection by PCR was performed to whole blood samples collected onto Whatman 3MM filter paper, from which DNA was extracted using Chelex $100^{\circ}$ $\left(\right.$ Sigma $\left.{ }^{\mathrm{rm}}\right)$. Amplification was carried out using a nested PCR assay to detect the $18 \mathrm{~s}$ rRNA gene of $P$. falciparum and $P$. vivax, according to previously published procedures [23]. Positive reaction controls consisted of DNA from the laboratory-adapted strain P. falciparum 3D7 and from a well characterized field isolate of $P$. vivax. Amplification products were resolved in a $2 \%$ agarose gel using ethidium bromide and visualized under UV light. Samples were processed once as long as controls were confirmed to operate in optimal conditions, otherwise, the assay was repeated until successful performance of controls.

\section{Statistical analyses}

The prevalence of gestational malaria and placental malaria was calculated according to the results of thick smear microscopy and PCR. The association between the distribution of frequencies among two variables was identified using $X^{2}$. Significance was established at $p<0.05 \%$. Data analyses were performed using EpiInfo 6.0 and SPSS $^{\circ} 10.0$.

\section{Ethical aspects}

The study protocol was reviewed and approved by: a) Ethics Committee of the Sede de Investigaciones Universitarias SIU, Universidad de Antioquia (Medellín, Colombia) (acta 07-32-126: project Colciencias code 111540820495, contract: 238-2007); b) Ethics Committee of the Instituto de Investigaciones Medicas, Universidad de Antioquia (acta 012: project Colciencias code 111549326134, contract 611 de 2009); c) Ethics Committee of Instituto de Investigaciones Medicas, Universidad de Antioquia (Medellin, Colombia) (project Regionalización-Universidad de Antioquia IIM 87642530). Each participant gave full informed consent according to the Helsinki convention and the Colombian regulations for this type of research. Each subject voluntarily accepted to participate in the study.
Women with a positive peripheral blood thick smear were treated, before hospital discharge, according to the recommendation of the Ministry of Health: a three-day course of chloroquine ( $25 \mathrm{mg} / \mathrm{kg}$ total dose) plus a 14-day course of primaquine $(0.25 \mathrm{mg} / \mathrm{kg} /$ day $)$ in $P$. vivax infection, or, in P. falciparum, a 3-day course of artesunate plus mefloquine at $200 \mathrm{mg}$ and $500 \mathrm{mg}$, respectively, per day in subjects aged $>13$ years (Antioquia department) or artemether plus lumefantrine $\left(\mathrm{Coartem}^{\circ}\right)$ twice a day for a total six doses in subjects $>34 \mathrm{~kg}$ (Cordoba department) [18].

\section{Results}

During the 34 months of the study (June 2008 - April 2011), a total of 121 parturient women were recruited at the local hospitals (eight records, out of the 129 expected subjects, had incomplete information). In general, subjects were young (mean age $=21.9 \pm 6.7$ ), the mean number of gravidity, including the current pregnancy, was $3.2 \pm 2.9$; all (but one) had a full term pregnancy $(38.8 \pm 2.1$ weeks), and their mean haemoglobin level was $10.6 \pm 0.13 \mathrm{~g} / \mathrm{dL}$ (mean $10.3 \mathrm{~g} / \mathrm{dL}$ in thick smear-gestational malaria positive and mean $10.6 \mathrm{~g} / \mathrm{dL}$ in thick smear-gestational malaria negative, $\mathrm{p}>0.05$ ). Review of clinical records confirmed that attendance to the antenatal clinic was late, scarce and irregular with a mean number of clinical evaluations of three and $<20 \%$ of mothers receiving $>5$ evaluations. In addition, application of a VDRL test during the antenatal period was performed in 70 subjects and one woman tested positive (titer 1:8). A total of 48 subjects were tested for HIV and all were negative. All participants were asymptomatic for malaria infection at delivery, and insecticide-treated nets were not used.

The frequency of gestational malaria was 9.1\% (11/121) by microscopy, and $14.0 \%(17 / 121)$ by PCR (Table 1 ). Meanwhile, the frequency of placental malaria was 3.3\% $(4 / 121)$ by microscopy and $16.5 \%(20 / 121)$ by PCR. In cases of gestational malaria, the frequency of submicroscopic parasitaemia (i.e. a positive PCR with negative microscopy) was $4.9 \%$ (14.0-9.1), and in cases of placental malaria this was $13.2 \%$ (16.5-3.3). The ratio between positive microscopy and positive PCR in gestational malaria was 1:1.5, and in placental malaria this was 1:5.

Among the 17 cases of gestational malaria diagnosed by PCR, $65 \%(11 / 17)$ were $P$. vivax, and $35 \%(6 / 17)$ were $P$. falciparum. The opposite was observed in placental malaria: P. falciparum was detected in 65\% (13/ $20)$, and $P$. vivax in $35 \%(7 / 20)$ of cases. All samples of umbilical cord blood were negative for malarial parasites by both tests.

Concurrence of gestational and placental malaria by microscopy was absent in the 110 subjects negative by microscopy and $36 \%$ of the 11 subjects with gestational 
Table 1 Comparison of frequencies of gestational and placental malaria according to thick smear microscopy and PCR

\begin{tabular}{lllll}
\hline A. Gestational Malaria & & & & \\
\hline & PCR & & & \\
& Negative & P. vivax & P. falciparum & Total \\
Microscopy & & & & \\
Negative & 103 & 4 & 3 & 110 \\
$\begin{array}{l}\text { P vivax } \\
\text { P falciparum }\end{array}$ & 0 & 7 & 0 & 7 \\
Mixed & 1 & 0 & 2 & 3 \\
Total & 0 & 0 & 1 & 1 \\
B. Placental Malaria & 104 & 11 & 6 & 121 \\
& PCR & & & \\
Microscopy & Negative & P. vivax & P. falciparum & Total \\
Negative & & & & \\
P vivax & 101 & 5 & 11 & 117 \\
P falciparum & 0 & 2 & 0 & 2 \\
Total & 0 & 0 & 2 & 2 \\
\hline & 101 & 7 & 13 & 121 \\
\hline
\end{tabular}

malaria evidenced placental infection. The frequency of simultaneous maternal and placental infection increased when PCR was performed: in the 104 gestational malaria negative subjects, 92\% (96/104) were placental malaria free, and in the 17 gestational malaria positive subjects, $71 \%(12 / 17)$ exhibited placental malaria. Therefore, the presence of parasites in the peripheral mother's blood was not always associated with placental infection, but absence of parasites in the mother's blood did not necessarily imply that the placenta was free of infection (Table 2).

History of gestational malaria was confirmed by review of clinical records in 26\% (31/120); cases were diagnosed by microscopy of mother's peripheral blood and were treated according to the Ministry of Health guidelines for malaria in pregnancy by the time of diagnosis and as detailed in the introduction section. In $87 \%(27 / 31)$ of cases of gestational malaria before delivery, at least one of the following was recorded: Plasmodium species, parasitaemia, or the gestational age at the time of diagnosis. When species was recorded (18/27 or $67 \%), 78 \%$ corresponded to $P$. vivax, and the remaining were $P$. falciparum. The mean parasitaemia in $P$. falciparum infections was $2,771 \pm 4,876$ parasites $/ \mu \mathrm{L}$ (median: 617; range: $40--18.060$ ).

Intrapartum microscopy or PCR of peripheral blood confirmed infection in up to $35.5 \%(11 / 31)$ of the subjects with a history of gestational malaria $(73 \%$ P. vivax, $18 \%$ P. falciparum, $9 \%$ mixed). In the 89 mothers without a history of gestational malaria, infection was detected at delivery in $7 \%$ (3.5\% each $P$. vivax and $P$. falciparum). A report of gestational malaria in the current pregnancy was significantly associated $(\mathrm{p}=$ 0.000121 ) with a positive PCR test at delivery and $94 \%$ $(84 / 89)$ of the women without a history of malaria were negative for gestational malaria at delivery (Table 3).

According the place of residency, prevalence of gestational malaria was $4 \%(3 / 71)$ in Turbo and $28 \%$ in Puerto

Table 2 Correlation between diagnosis of gestational malaria and placental malaria by two diagnostic methods (A. Thick smear microscopy and B. PCR)

\begin{tabular}{|c|c|c|c|c|}
\hline \multicolumn{5}{|c|}{ A. Thick smear microscopy } \\
\hline & \multicolumn{4}{|c|}{ Placental malaria } \\
\hline & Negative & P. vivax & P. falciparum & Total \\
\hline \multicolumn{5}{|c|}{ Gestational malaria } \\
\hline Negative & 110 & 0 & 0 & 110 \\
\hline$P$ vivax & 5 & 2 & 0 & 7 \\
\hline P falciparum & 2 & 0 & 1 & 3 \\
\hline Mixed & 0 & 0 & 1 & 1 \\
\hline Total & 117 & 2 & 2 & 121 \\
\hline \multicolumn{5}{|l|}{ B. PCR } \\
\hline & \multicolumn{4}{|c|}{ Placental malaria } \\
\hline & Negative & P. vivax & P. falciparum & Total \\
\hline \multicolumn{5}{|c|}{ Gestational malaria } \\
\hline Negative & 96 & 1 & 7 & 104 \\
\hline$P$ vivax & 5 & 6 & 0 & 11 \\
\hline$P$ falciparum & 0 & 0 & 6 & 6 \\
\hline Total & 101 & 7 & 13 & 121 \\
\hline
\end{tabular}


Table 3 Correlation of diagnosis of gestational or placental malaria at delivery by PCR and a history of gestational malaria during pregnancy

\begin{tabular}{lllll}
\hline A. Gestational malaria* & & & & \\
\hline & Negative & P. vivax & P. falciparum & Total \\
History of gestational & & & & \\
malaria & & & & \\
Negative & 84 & 3 & 2 & 89 \\
Positive & 20 & 8 & 3 & 31 \\
Total & 104 & 11 & 5 & 120
\end{tabular}

B. Placental malaria ${ }^{+}$

Negative P. vivax P. falciparum Total

History of gestational

malaria

\begin{tabular}{lllll} 
Negative & 83 & 1 & 5 & 89 \\
Positive & 18 & 6 & 7 & 31 \\
Total & 101 & 7 & 12 & 120 \\
\hline
\end{tabular}

${ }^{*} p=0.000121$ for species, $p=0.000094$ for presence-absence of infection,

${ }^{+} p=0.000010$ for species and $p=0.000014$ for presence-absence of infection.

Libertador (14/50). Meanwhile, the prevalence of placental malaria was $4 \%(3 / 71)$ and $34 \%(17 / 50)$, respectively. Therefore, both gestational and placental malaria were significantly associated to the place of residency $(\mathrm{p}=$ 0.001040 and $p=0.000049$, respectively) (Table 4 ). No significant association could be confirmed between parity and presence of malarial infection by any of the tests applied $(p>0.153)$, which means that regardless of being in their first, second, third or $>3$ rd pregnancy, all women had the same risk of gestational malaria and placental malaria.

In one subject a stillbirth was reported. This occurred in an 18 year-old mother in her first pregnancy and with a history of gestational malaria by $P$. vivax. Maternal haemoglobin at delivery was $9.1 \mathrm{~g} / \mathrm{dL}$ and the gestational age was 27 weeks. Malaria-specific results for this case

Table 4 Frequencies of diagnosis of gestational and placental malaria at delivery by PCR according to locality

\begin{tabular}{lllll}
\hline A. Gestational malaria* & & & & \\
\hline & Negative & P. vivax & P. falciparum & Total \\
Turbo & 68 & 2 & 1 & 71 \\
Puerto Libertador & 36 & 9 & 5 & 50 \\
Total & 104 & 11 & 6 & 121 \\
B. Placental malaria & & & &
\end{tabular}

B. Placental malaria ${ }^{+}$

Negative P. vivax P. falciparum Total

\begin{tabular}{lllll} 
Turbo & 68 & 0 & 3 & 71 \\
Puerto Libertador & 33 & 7 & 10 & 50 \\
Total & 101 & 7 & 13 & 121 \\
\hline
\end{tabular}

${ }^{*} p=0.001040$ for species, $p=0.000211$ for presence-absence of infection, ${ }^{+} p=0.000049$ for species and $p=0.000014$ for presence-absence of infection. confirmed maternal infection with $P$. vivax and $P$. falciparum by microscopy whereas only $P$. falciparum was detected by PCR. Placental infection by $P$. falciparum was detected by both tests and the cord blood was negative for infection.

\section{Discussion}

The current report on the prevalence of gestational, placental and congenital malaria in parturient women from a highly malaria endemic region of Colombia, further defines the epidemiology of this infection in the country. A major limitation of the study is the absence of followup at the antenatal clinic and the recruitment in a passive fashion. This resulted in the inclusion of a population which might not precisely reflect the dimension of the malaria problem during pregnancy. Nevertheless, the fact that all studied subjects were asymptomatic for malaria, suggests that the figures herein published underestimate the actual frequency of gestational malaria. Current ongoing studies, overcome this limitation by including recruitment at the antenatal clinics and follow-up until delivery.

It is important to highlight that during the recruitment of subjects for the current study, the health authorities of Uraba carried out an intense malaria control programme from 2007 until 2009 with a major impact on the frequency of malaria, as reported herein. The programme, named "Papa Luis", consisted of massive anti-malarial administration (chloroquine), biologic control of Anopheles spp. larvae, swamp drainage and indoor residual spraying. A programme as such was not implemented in Cordoba. In addition, both study regions were deeply affected by intense and continuous rainy seasons during 2008, 2010 and the first six months of 2011, which also contributed to a reduction in the reported number of cases concomitantly with the rains, followed by a rise of cases as they decline. Finally, attendance of mothers at any health facility was seriously affected by the political instability and social insecurity prevalent in the region. All these factors contributed to reduced attendance at hospitals, increased the recruitment period and, very probably, impacted the results after inclusion of subjects resident in and around urban centers. Nevertheless, in Puerto Libertador the frequency of gestational malaria was seven times that recorded in Turbo ( $4 \% v s$. $28 \%$ ) and placental malaria was eight-fold that observed in Turbo ( $4 \%$ vs. 34\%). Climate conditions and turmoil from violence are similar in both regions and only the application of control programmes seems to differ between the two localities. Major fluctuations in the frequency of gestational and pregnant malaria have also been reported in other endemic countries [24,25].

Studies on gestational placental or congenital malaria are scarce in America in comparison to Africa [4-6,26,27] 
and most recent reports come from Colombia [7,9-12] and Brazil $[4,26]$. In the Brazilian Amazon, among 1,699 women with malaria, the prevalence of gestational malaria was $11.7 \%$ and $P$. vivax was confirmed in $83 \%$ of cases [25]. In a previous report from Rio Branco (Brazil) among 33,420 women who attended the hospital, 445 had gestational malaria resulting in a prevalence of $1.4 \%$; $P$. vivax was detected in $53 \%$ of them [24]. In the current report, the prevalence of gestational malaria was $9.1 \%$ by microscopy and $14 \%$ by PCR, while the prevalence of placental malaria was $3.3 \%$ by microscopy and $16.5 \%$ by PCR. The positivity rates by microscopy, for the both gestational and placental malaria, are lower than those previously reported in $2004-2006$ in the same region (10-14\% gestational malaria and $9-12 \%$ placental malaria) [7-9], probably as a result of the intervention measures and the climate conditions above detailed.

As for congenital malaria, the current report confirmed previous observations made by other authors on the low frequency of infection in cord blood $(2.5 \%)$ in relation with higher rates of gestational malaria (9.5\%) [11]. Several factors might explain the relative protection of the foetus to acquisition of congenital malaria, namely the degree of previously acquired immunity of the mother [28], the proportion of foetal haemoglobin [28], and the higher frequency of $P$. vivax infection, which in theory, fails to sequester in placenta, among others. The fact that subjects recruited in this study were asymptomatic yet they presented with parasitaemia, strengthens the important role of passive transfer of maternal antimalarial antibodies in the protection against congenital malaria. This subject is under exploration in specificallydesigned ongoing studies.

Attendance to the antenatal clinic was inadequate in coincidence with previous reports from the region [7], and the number of women tested for infections such as syphilis and HIV was alarmingly low. Insecticide-treated net usage is uncommon in Colombia $(<20 \%)$, as is indoor residual spraying [29]. A similar situation is seen in other countries of the Americas. The complete failure to use insecticidetreated nets by subjects enrolled in this study, reflects the lack of government will to effectively address the malaria problem. Furthermore, intermittent preventive therapy during pregnancy is not applied on a routine basis in Colombia or elsewhere in the Americas, despite being a proven control measure in most African countries [30]. Failure to apply any of the above-mentioned control measures, in addition to the lack of access to adequate antenatal care, the precarious life conditions and the extreme political violence of most malaria endemic regions perpetuate the high risk of malaria transmission, among other infectious conditions, in mothers and their children.

The results reported herein confirm the higher frequency of gestational and placental malaria detected by
PCR compared to microscopy as reported previously in this and other endemic regions [9,31,32]. Furthermore, recent studies in Colombia confirm the higher sensitivity of a quantitative PCR over a standard nested PCR, to detect gestational and placental malaria [33]. However, in field conditions, application of any molecular based approach remains impractical and innovative solutions are highly welcomed by field researchers. Molecular tools allow identification of sub-microscopic infections, which in the current studied represented $4.9 \%$ of gestational malaria and $13.2 \%$ of placental malaria, but no effect on newborn's weight or mother's haemoglobin could be confirmed. A recent review on submicroscopic Plasmodium infection during pregnancy concluded that the risk of anaemia and low birth weight infants are increased in positive cases [34]. Following up studies, with precise assessment of clinical outcomes in infected cases might help to elucidate the consequences of submicroscopic malaria during pregnancy in this region of the continent.

The presence of a positive peripheral thick smear at delivery seems insufficient to predict the existence of placental infection, but a negative smear cannot guarantee an uninfected placenta. Therefore, due to the potential risk of malaria in the mother, clinicians should presume placental infection in all cases of gestational malaria. Of major importance in the clinical practice is the finding that a positive history of gestational malaria correlated with gestational and/or placental malaria at delivery, regardless of adequate anti-malarial treatment of the original episode. Since $P$. falciparum seems to remain susceptible to artemisinin-based combination therapy [35], possible explanations for placental parasite persistence include sequestration of parasites in the placenta, $P$. vivax relapses and erroneous species identification (a documented limitation of microscopy) during the primary episode.

The current report confirms the findings of previous researchers which report gestational and placental malaria as serious public health problems in north-west Colombia. Moreover, during the period of study, the local health authorities failed to observe the official recommendation since routine thick smear of peripheral blood was not practiced at antenatal visits, delaying diagnosis and treatment. This, combined with the social inequity faced by the women and families inhabiting the region; and the particular cultural frame and living conditions, contributes to perpetuate the problem $[36,37]$. Malaria in Colombia is a disease of deprived and economically unstable populations, which are also poorly attended by the health services. Among them, women are the most vulnerable from the social perspective since they are particularly susceptible to develop malaria complications during pregnancy and lack access to economic and health resources [38-40]. 


\section{Conclusions}

The following conclusions were reached: 1) the problem of malaria during pregnancy and placental malaria is serious in north-west Colombia; 2) the history of gestational malaria constitutes an indicator of gestational and placental malaria at delivery; 3) the risk of congenital malaria is low; 4) measures should be implemented by regional and national health authorities to guarantee that recommendations regarding malaria testing at the antenatal clinics are fulfilled.

\section{Competing interests}

The authors declare that they have no competing interests.

\section{Authors' contributions}

$\mathrm{OA}$ and EA performed field work and processed blood samples. AM supervised overall design and development and wrote the manuscript, JC conceived the Project, designed the protocol and supervised overall design and development. All authors read and approved the final manuscript.

\section{Acknowledgments}

The authors are grateful to Dr Stephanie Yanow for reviewing and proof reading the manuscript.

\section{Financial support}

Colciencias (projects 11150417041, 111540820495, 111549326134); Codi-Regionalización-Universidad de Antioquia (project IIM 8764-2530); Estrategia Sostenibilidad-Universidad de Antioquia 2013-2014; Universidad de Antioquia.

Received: 9 April 2013 Accepted: 17 September 2013 Published: 23 September 2013

\section{References}

1. Rogerson SJ, Mwapasa V, Meshnick SR: Malaria in pregnancy: linking immunity and pathogenesis to prevention. Am J Trop Med Hyg 2007, 77:14-22.

2. Desai M, ter Kuile FO, Nosten F, McGready R, Asamoa K, Brabin B, Newman $\mathrm{RD}$ : Epidemiology and burden of malaria in pregnancy. Lancet Infect Dis 2007, 7:93-104.

3. Almeida LB, Barbosa MD, Martinez-Espinosa FE: Malaria among women aged 10 to 49 years, according to SIVEP-Malaria, Manaus, State of Amazonas, 2003-2006. Rev Soc Bras Med Trop 2010, 43:304-308.

4. Carvalho BO, Matsuda JS, Luz SL, Martinez-Espinosa FE, Leite JA, Franzin F, Orlandi PP, Gregoracci GB, Lacerda MV, Nogueira PA, Costa FT: Gestational malaria associated to Plasmodium vivax and Plasmodium falciparum placental mixed-infection followed by foetal loss: a case report from an unstable transmission area in Brazil. Malar J 2011, 10:178.

5. Gómez E, López E, Ache A: Malaria and pregnancy. San Isidro parish, municipality Sifontes, state of Bolívar, Venezuela, 2005-2006. Invest Clin 2009, 50:455-464.

6. Parekh F, Hernandez J, Krogstad D, Casapia W, Branch O: Prevalence and risk of Plasmodium falciparum and $P$. vivax malaria among pregnant women living in the hypoendemic communities of the Peruvian Amazon. Am J Trop Med Hyg 2007, 77:451-457.

7. Carmona-Fonseca J, Maestre A: Incidencia de la malaria gestacional, congénita y placentaria en Urabá (Antioquia, Colombia), 2005-2007. Rev Col Obst Ginecol 2009, 60:12-26.

8. Carmona-Fonseca J, Franco A, Arango E, Agudelo O, Maestre A: Now ICT malaria $\mathrm{Pf} / \mathrm{Pv}^{\circledast}$ frente a microscopía (gota gruesa-extendido) para diagnóstico de malaria en Urabá (Colombia). latreia 2010, 23:137-145.

9. Campos I, Uribe M, Cuesta C, Franco-Gallego A, Carmona-Fonseca J, Maestre A: Diagnosis of gestational, congenital, and placental malaria in colombia: comparison of the efficacy of microscopy, nested polymerase chain reaction, and histopathology. Am J Trop Med Hyg 2011, 84:929-935.

10. Piñeros JG, Tobon-Castaño A, Alvarez G, Portilla C, Blair S: Maternal clinical findings in malaria in pregnancy in a region of northwestern Colombia. Am J Trop Med Hyg 2013, 89:520-526.
11. Piñeros-Jiménez JG, Álvarez G, Tobón A, Arboleda M, Carrero S, Blair S: Congenital malaria in Urabá, Colombia. Malar J 2011, 10:239.

12. Tobón-Castaño A, Solano MA, Sánchez LG, Trujillo SB: Intrauterine growth retardation, low birth weight and prematurity in neonates of pregnant women with malaria in Colombia. Rev Soc Bras Med Trop 2011, 44:364-370.

13. Carmona-Fonseca J: La malaria en Colombia, Antioquia y las zonas de Urabá y Bajo Cauca: panorama para interpretar la falla terapéutica antimalárica. Parte 2. latreia 2004, 17:34-53.

14. Carmona-Fonseca J: La malaria en Colombia, Antioquia y las zonas de Urabá y Bajo Cauca: panorama para interpretar la falla terapéutica antimalárica Parte 1. latreia 2003, 16:299-318.

15. Corredor V, Murillo C, Echeverry DF, Benavides J, Pearce RJ, Roper C, Guerra AP, Osorio L: Origin and dissemination across the Colombian Andes mountain range of sulfadoxine-pyrimethamine resistance in Plasmodium falciparum. Antimicrob Agents Chemother 2010, 54:3121-3125.

16. Restrepo E, Carmona-Fonseca J, Maestre A: Plasmodium falciparum: high frequency of pfcrt point mutations and emergence of new mutant haplotypes in Colombia. Biomedica 2008, 28:523-530.

17. Osorio L, Pérez LP, González IJ: Assessment of the efficacy of antimalarial drugs in Tarapacá, in the Colombian Amazon basin. Biomedica 2007, 27:133-140.

18. Ministerio de la Proteccion Social. Guia de manejo de la malaria; 2010 [http://www.acin.org/acin/new/Portals/0/Templates/guia\%20de\%20atencion \%20clinica\%20de\%20malaria\%202010.pdf].

19. Dirección Seccional de Salud de Antioquia-DSSA: Enfermedades Transmitidas por Vectores 2000-2010. http://www.dssa.gov.co/index.php/documentos/ doc_download/669-enfermedades-transmitidas-por-vectores.

20. Secretaría de Desarrollo de la Salud de Córdoba-SDSC. Programa Prevención y Control de Enfermedades Transmitidas por Vectores; 2009. http://www. saludcordoba.gov.co/portal/descargas/sivigila2010/presentaciones/ presentacion_etv.pptx.

21. Carmona-Fonseca J, Arango E, Maestre A: Placental Malaria in Colombia: Histopathologic Findings in Plasmodium vivax and $P$. falciparum Infections. Am J Trop Med Hyg 2013, 88:1093-1101.

22. López-Antuñano F: Diagnóstico microscópico de los parásitos de la malaria en la sangre. In Diagnóstico de malaria, Volume 512. Washington: OPS-OMS; 1988:39-50.

23. Snounou G, Viriyakosol S, Zhu XP, Jarra W, Pinheiro L, Do Rosario VE Thaithong S, Brown KN: High sensitivity of detection of human malaria parasites by the use of nested polymerase chain reaction. Mol Biochem Parasitol 1993, 61:315-320.

24. Jarude $\mathrm{R}$, Trindade $\mathrm{R}$, Tavares-Neto J: Malária em grávidas de uma maternidade pública de Rio Branco (Acre, Brasil). Rev Bras Ginecol Obstet 2003, 25:149-154.

25. Martínez-Espinosa FE, Daniel-Ribeiro CT, Alecrim WD: Malaria during pregnancy in a reference centre from the Brazilian Amazon: unexpected increase in the frequency of Plasmodium falciparum infections. Mem Inst Oswaldo Cruz 2004, 99:19-21.

26. Souza RM, Ataíde R, Dombrowski JG, Ippólito V, Aitken EH, Valle SN, Álvarez JM, Epiphanio S, Epiphânio S, Marinho CR: Placental histopathological changes associated with Plasmodium vivax infection during pregnancy. PLoS Negl Trop Dis 2013, 7:e2071.

27. Parekh F, Davison B, Gamboa D, Hernandez J, Branch O: Placental histopathologic changes associated with subclinical malaria infection and its impact on the fetal environment. Am J Trop Med Hyg 2010, 83:973-980.

28. Uneke C: Congenital malaria: an overview. Tanzan J Health Res 2011, 13:16.

29. WHO: World malaria report: Geneva. Switzerland: World Health Organization; 2011.

30. Gosling RD, Cairns ME, Chico RM, Chandramohan D: Intermittent preventive treatment against malaria: an update. Expert Rev Anti Infect Ther 2010, 8:589-606.

31. Mohammed AH, Salih MM, Elhassan EM, Mohmmed AA, Elzaki SE, El-Sayed BB, Adam I: Submicroscopic Plasmodium falciparum malaria and low birth weight in an area of unstable malaria transmission in Central Sudan. Malar J 2013, 12:172.

32. Omer $S$, Khalil E, Ali H, Sharief A: Submicroscopic and multiple Plasmodium falciparum infections in pregnant Sudanese women. N Am J Med Sci 2011, 3:137-141.

33. Arango EM, Samuel R, Agudelo OM, Carmona-Fonseca J, Maestre A, Yanow SK: Molecular detection of malaria at delivery reveals a high frequency 
of submicroscopic infections and associated placental damage in pregnant women from northwest Colombia. Am J Trop Med Hyg 2013, 89:178-183.

34. Arango E, Maestre A, Carmona-Fonseca J: [Effect of submicroscopic or polyclonal Plasmodium falciparum infection on mother and gestation product: systematic review]. Rev Bras Epidemiol 2010, 13:373-386.

35. Vásquez AM, Sanín F, Alvarez LG, Tobón A, Ríos A, Blair S: [Therapeutic efficacy of a regimen of artesunate-mefloquine-primaquine treatment for Plasmodium falciparum malaria and treatment effects on gametocytic development]. Biomedica 2009, 29:307-319.

36. Correa A, Arias M, Carmona-Fonseca J: Equidad e igualdad sociales y sanitarias. Necesidad de un marco conceptual científico. Medicina Social 2011, 6:1-9.

37. Carmona-Fonseca J, Arias M, Correa A, Lemos M: Malaria gestacional y condiciones de vida. Medicina Social 2011, 6:97-107.

38. Breman JG, Alilio MS, Mills A: Conquering the intolerable burden of malaria: what's new, what's needed: a summary. Am J Trop Med Hyg 2004, 71:1-15.

39. Kuate Defo B: Effects of socioeconomic disadvantage and women's status on women's health in Cameroon. Soc Sci Med 1997, 44:1023-1042.

40. Steketee RW: Pregnancy, nutrition and parasitic diseases. J Nutr 2003, 133:1661S-1667S.

doi:10.1186/1475-2875-12-341

Cite this article as: Agudelo et al:: Prevalence of gestational, placental and congenital malaria in north-west Colombia. Malaria Journal 2013 12:341.

\section{Submit your next manuscript to BioMed Central and take full advantage of:}

- Convenient online submission

- Thorough peer review

- No space constraints or color figure charges

- Immediate publication on acceptance

- Inclusion in PubMed, CAS, Scopus and Google Scholar

- Research which is freely available for redistribution 